Bangladesh J. Zool. 40(1): 51-58, 2012

\title{
STUDIES ON THE BIODIVERSITY OF ASEPTATE GREGARINE PARASITE FROM THE OLIGOCHAETE HOST OF BANGLADESH
}

\author{
Sutapa Sarkar and Probir K. Bandyopadhyay* \\ Parasitology Laboratory, Department of Zoology, University of Kalyani, \\ Kalyani- 741235, West Bengal, India
}

\begin{abstract}
Biodiversity studies in search of endoparasitic acephaline gregarines of the earthworms of Dhaka, Bangladesh, revealed a new species under the genus Nematocystis Hesse, 1909. The species was obtained from the seminal vesicles of the earthworm Metaphire peguana Rasa, 1890. It is a perfectly ribbon like organism, solitary, cylindrical, with several bulges and foldings in the middle portion of the body, especially in mature forms. Mature gamont measures 1955.85-1989.0 (1970.215 \pm 13.830) $\mu \mathrm{m}$ in length and 48.62-53.04 (51.714 \pm $2.135) \mu \mathrm{m}$ in width. Nucleus small and rounded, measures 26.52-33.15 (29.835 \pm 2.992) $\mu \mathrm{m}$ in length and $17.68-22.01(19.448 \pm 2.282) \mu \mathrm{m}$ in width. Gametocysts spherical with two approximately equal sized gametocytes. It measures 110.05$121.55(116.24 \pm 4.908) \mu \mathrm{m}$ in length and 88.04-99.45 (93.925 \pm 5.823$) \mu \mathrm{m}$ in width. Oocysts biconical, measuring 22.1-30.94 (26.962 \pm 3.870$) \mu \mathrm{m} \times 11.05$ $15.47(13.26 \pm 2.08) \mu \mathrm{m}$.
\end{abstract}

Keywords: Gregarine, parasite, Nematocystis bangladeshensis sp.nov, seminal vesicles, earthworm, Metaphire peguana, Bangladesh.

\section{INTRODUCTION}

Levine (1977) listed 27 species of Nematocystis Hesse, 1909. Segun (1978) describe a species under the genus Nematocystis. Later on Pradhan and Dasgupta (1980) and Bandyopadhyay et al. (2005, 2006, 2007), Mallik et al. (2009 and 2010) worked a lot on Nematocystis. A total 39 species of Nematocystis have been reported from oligochaete hosts, of which only 15 species have been from India. The present paper deals with the description of a new species of Nematocystis obtained from the seminal vesicles of the earthworm Metaphire peguana Rasa, 1890 collected from Dhaka, Bangladesh for the first time.

The present study is related with the biodiversity of the acephaline gregarine from the oligochaete host of Bangladesh. The objective of the present study is to describe a new species of aseptate gregarine from the oligochaete host, Bangladesh.

\section{MATERIAL AND METHODS}

The biotic survey of gregarine parasites in oligochaetes was performed in Dhaka, Bangladesh. Samplings were carried out in search of earthworm hosts in Dhaka, Bangladesh. The host earthworms were collected during the months of April -June 2011 from the drainage soil and the collected earthworms were kept

*Corresponding author: E-mail: prabir0432@hotmail.com 
in soil in a tub and taken to the laboratory alive. Some of the earthworms were dissected while alive and their seminal vesicles were carefully removed. These were placed on clean glass slide with a drop of $0.6 \% \mathrm{NaCl}$ solution. A thin film of seminal fluid was drawn out on a slide covered with a cover slip for the examination of living protozoan under a light microscope. After initial study of living protozoans, the content of the seminal vesicles was semidried and fixed in Schaudin's fluid for 20 minutes. The smears were stored in $70 \%$ ethanol for the removal of mercuric chloride. The slides were then passed through a descending series of alcohol (five minutes each) and placed in distilled water. These were transferred to a 3\% Iron Alum solution (Over night) and stained with Heidenhain's hematoxylin for 20 minutes. Differentiation was done with $1 \%$ iron alum solution under the low power objective lens of the light microscope. The slides were then washed thoroughly, dehydrated in an ascending series of alcohol, cleared in xyline and mounted in DPX. All measurements were made with a calibrated ocular micrometer. In each case minimum and maximum values are given, followed in parentheses by arithmetic mean, standard deviation. For statistical analysis measurements of 20 specimens were taken into account. Photomicrographs were taken using an Olympus light microscope (model CH-2) and Olympus digital camera (model CX41). The methods of describing the shapes of planes and solids have been done following Clopton (2004).

\section{RESULTS AND DISCUSSION}

$\begin{array}{lll}\text { Phylum } & : & \text { Apicomplexa Levine, } 1977 \\ \text { Class } & : & \text { Sporozoa Labbe, } 1899 \\ \text { Order } & : & \text { Eugregarinida Lager, } 1900 \\ \text { Family } & : & \text { Monocystidae Biitschli } 1882 \\ \text { Sub family } & : & \text { Monocystinae Bhatia, } 1930 \\ \text { Genus } & : & \text { Nematocystis Hesse, } 1909\end{array}$

Nematocystis bangladeshensis sp. nov (Figs 1-4, Tables 1-2)

Mature gamont length (GL) 1955.85-1989.0 (1970.215 \pm 13.830$) \mu \mathrm{m}$ and width $(\mathrm{GW}) 48.62-53.04(51.714 \pm 2.135) \mu \mathrm{m}$. Gamont width at the middle part 77.35-88.04 (83.759 \pm 4.825$) \mu \mathrm{m}$ and gamont width at the posterior end 22.1$33.15(28.73 \pm 5.706) \mu \mathrm{m}$. Nucleus small and rounded. The length of nucleus (LN) 26.52-33.15 $(29.835 \pm 2.992) \mu \mathrm{m}$ and width (WN) 17.68-22.01 (19.448 \pm 2.282) $\mu \mathrm{m}$. Gametocyst spherical with two approximately equal sized gametocytes. Length of gametocyst (LG) 110.05-121.55 (116.24 \pm 4.908$) \mu \mathrm{m}$ and 
width (WG) 88.04-99.45 (93.925 \pm 5.823$) \mu \mathrm{m}$. Oocyst biconical. Length of oocyst, 22.1-30.94 (26.962 \pm 3.870$) \mu \mathrm{m}$ and width $11.05-15.47(13.26 \pm 2.08) \mu \mathrm{m}$.
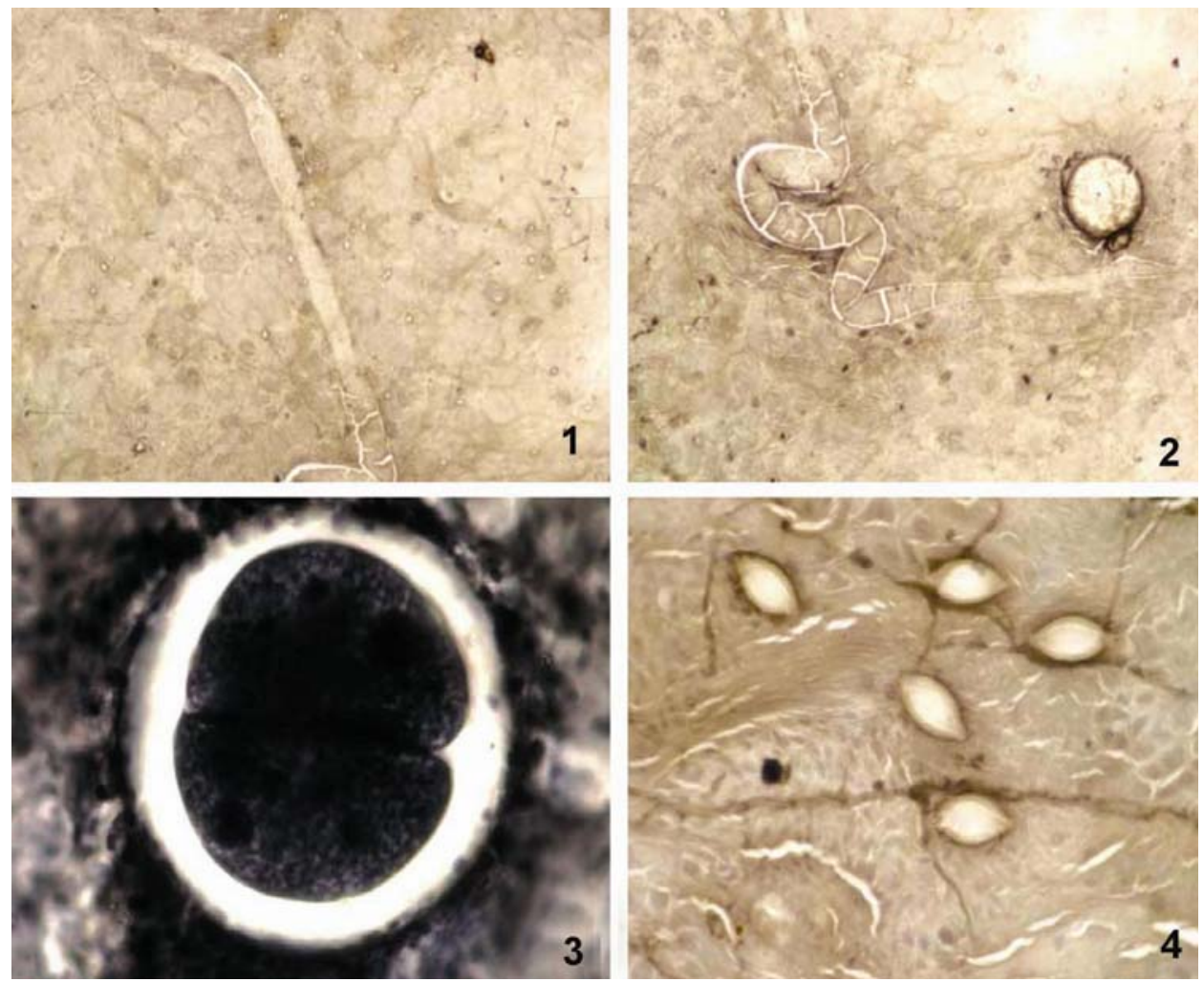

Figs 1-4: Photomicrographs of different stages of the life cycle of Nematocystis bangladeshensis sp.nov. obtained from the seminal vesicles of the earthworm Metaphire peguana. 1. Anterior part of mature gamont. 2. Posterior part of mature gamont. 3. Gametocyst. 4. Oocysts. Magnifications : $15 \times 40(1-3), 15 \times 100$ (4).

With the characters of the genus Nematocystis Hesse, 1909 as given by Levine (1977) "Gamonts large, cylindrod, nematoid, often with mucorn at anterior end solitary, oocyst biconical." In the present form the gamonts are solitary and cylindrical, with an enlarged head. The anterior end is usually swollen and rounded, but the edges are not perfectly parallel, because of some foldings. The posterior end ended gradually to a point. The mucorn well developed, made up of smooth hyalin protoplasm. Ectoplasm and epicyte thin, transparent and quite delicate. Sarcocyte is composed of dense homogeneous protoplasm. Endoplasm is composed of dense protoplasm without any paraglycogen grain and in the head region it is more transparent in comparison to other portion of the body. Nucleus elongated and present at the anterior end. 
Gametocyst spherical with two approximately equal sized gametocytes, Oocyst biconical. The presence of large and long solitary nematode like gamont and biconical oocyst justifies the inclusion of the present form under genus Nematocystis Hesse 1909.

Table 1. Summary of Measurements $(\mu \mathrm{m})$ of different body parts of the gamonts, gametocysts and oocysts are presented below.

\begin{tabular}{lccc}
\hline $\begin{array}{l}\text { Different body parts of the gamonts, } \\
\text { gametocysts and oocyst. }\end{array}$ & Mean & Range & Standard deviation \\
\hline Gamont length (GL) & 1970.215 & $1955.85-1989.0$ & 13.83 \\
Gamont width (GWa) (anterior part) & 51.714 & $48.62-53.04$ & 2.135 \\
Gamont width (GWm) (Middle part) & 83.759 & $77.35-88.4$ & 4.825 \\
Gamont width (GWp) (Posterior part) & 28.73 & $22.1-33.15$ & 5.706 \\
Protruted anterior part length & 24.31 & $110.5-132.6$ & 2.329 \\
Length of nucleus (LN) & 29.835 & $26.52-33.15$ & 2.992 \\
Width of nucleus (WN) & 19.448 & $17.68-22.1$ & 2.282 \\
Length of gametocyst (LG) & 116.24 & $110.5-121.55$ & 4.908 \\
Width of gametocyst (WG) & 93.925 & $88.4-99.45$ & 5.823 \\
Length of oocyst (LO) & 26.962 & $22.1-30.94$ & 3.870 \\
Width of oocyst (WO) & 13.26 & $11.05-15.47$ & 2.08 \\
\hline
\end{tabular}

The species under discussion has some peculiar characters (cylindrical body with roughly parallel sides ending in a ' $\mathrm{v}$ ' shaped pointed posterior end, several folding along the middle part of the body, anterior end is lobe like and with mucorn). While comparing the species it has some similarities with Nematocystis levinei, $N$. gardenica and $N$. kalyaniensis, but dissimilarities are predominant with N. stephensoni (Bhatia and Setna 1926), N. bayrami, N. vinodae. The length of the gamont of present form is greater than that of $N$. bayrami, $N$. gardenica, $N$. kalyaniensis, $N$. vinodae, $N$. majumdari and also from $N$. stephensoni. But, it does not show much difference with the length of $N$. indica and $N$. Levinei. The width of the gamont of $N$. indica and $N$. levinei has some differences with the present form. The shape of the present form also varies with the earlier described species of Nematocystis. The size and position of the nucleus also differs with the previously described species. In $N$. indica the nucleus is elongated. Whereas, it is spherical in $N$. kalyaniensis, rounded and compact in $N$. majumdari and $N$. bayrami, oval in $N$. gardenica, ellipsoidal in $N$. stephensoni.

The gametocyst of $N$. indica possess two almost equal gametocytes which resembles the present species. But in $N$. bayrami, the gametocyst bears two unequal sized gametocytes. The shape of the Oocyst in the present species differs from that of $N$. gardenica and $N$. kalyaniensis, but it shows some degree of similarities with the previously described species in regard to body dimensions. Moreover, the hosts are also different. N. gardenica, $N$. kalyaniensis 


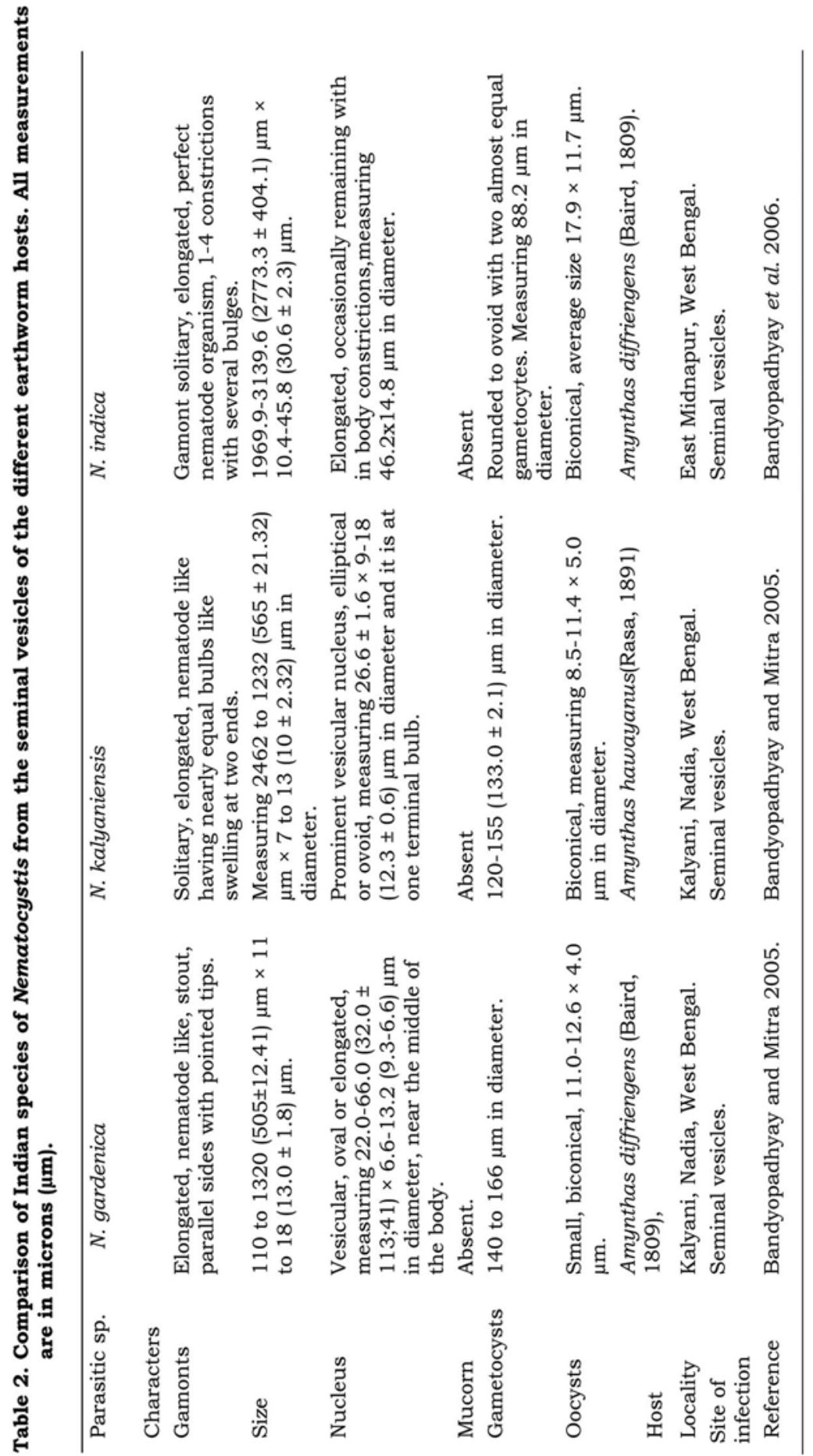




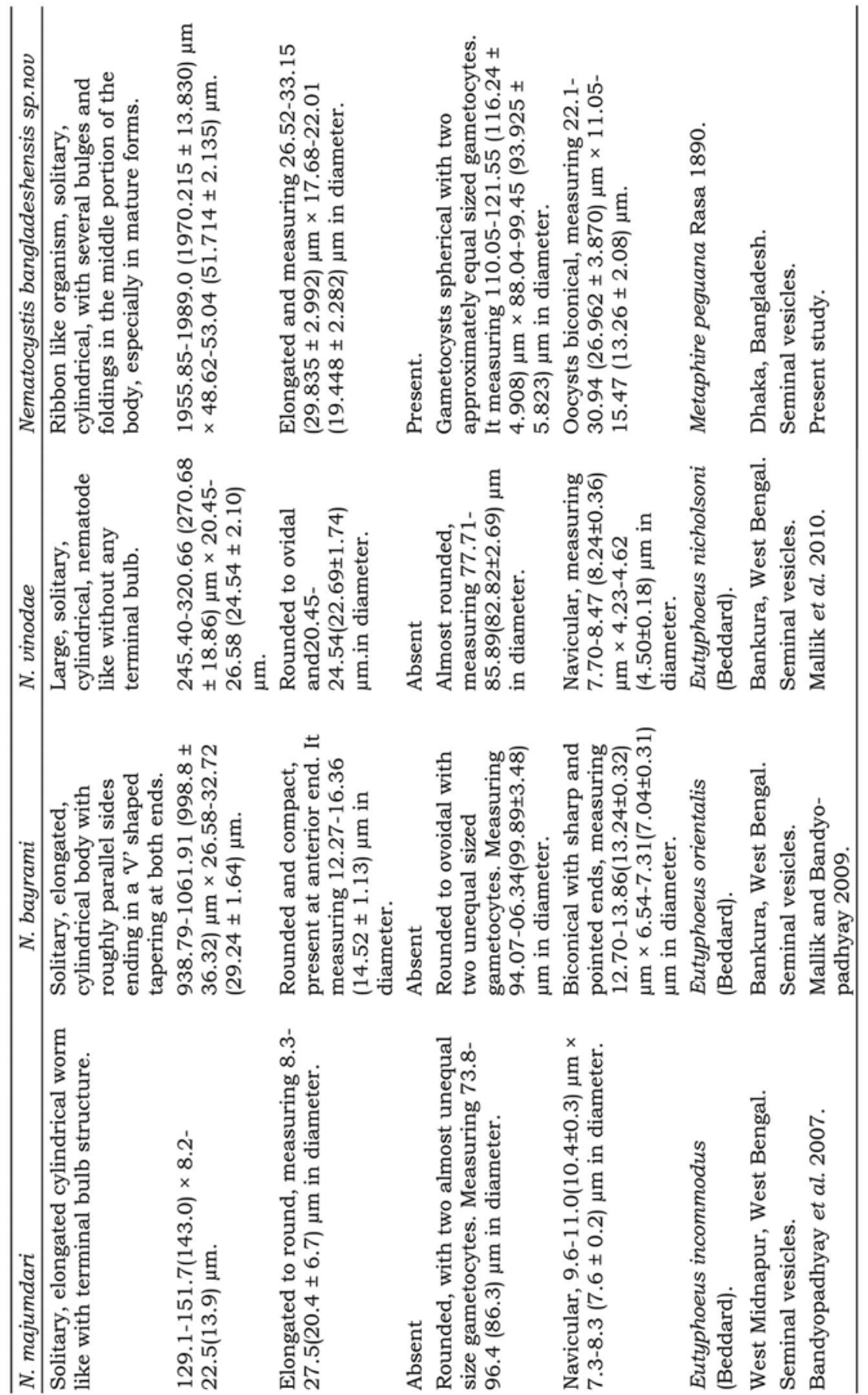


and $N$. indica were described from Amynthas diffriengens and Amynthas hawayanus whereas $N$. bayrami and $N$. vinodae from Eutyphoeus orientalis and Eutyphoeus nicholsoni, respectively of Indian subcontinent. On the other hand, the host of the present form is obtained from Metaphire peguana of Bangladesh. So it is evident, that the present form obtained from the seminal vesicles of Metaphire peguana is totally different from the other species under the genus Nematocystis described earlier. It differs in shape, size and distribution pattern also and is found for the first time from different geographical region, i.e. Bangladesh. Considering all these aspects the present form is a new species and hence the name Nematocystis bangladeshensis sp. nov. is being proposed.

\section{TAXONOMIC SUMMARY}

Species: Nematocystis bangladeshensis sp. nov.

Name of the Host: Metaphire peguana Rasa, 1890.

Locality: Dhaka (Lat, 23 43' 23" N, Long, 90²4' 31" E) Bangladesh.

Habitat: Seminal Vesicles.

No. of the specimens examined: 20

No. of the host infested: 10

Prevalence: 10/20 (50\%)

Material examined: Holotype no: 301/BD/ DH/11 deposited at the Parasitology laboratory of the Department of Zoology, University of Kalyani, Kalyani 741235, West Bengal, India. Paratype no: 302/BD/DH/2/11 deposited at the Parasitology Laboratory of the Department of Zoology, University of Kalyani, Pin- 741235, West Bengal, India.

Etymology: The name of the species is given after the name of the country from where the hosts have been collected.

Concluding remarks: The biodiversity study of protozoan parasites from oligochaete hosts of Bangladesh revealed that the seminal vesicle of Mataphire peguana are infected with a new species of the genus Nematocystis and while compairing the other species described earlier, it seems to be new to science and a new name has been proposed in this communication.

Acknowledgments: One of the authors (SS) is thankful to the authorities of the University of Kalyani, Kalyani, West Bengal for extending their permission to work at the Parasitology Laboratory of the Department of Zoology, and to Dr. C.K. Mandal of ZSI, Kolkata, India for identification of the host specimens. 


\section{LITERATURE CITED}

BANDYOPADHYAY, P.K. and MITRA, A.K. 2005. Observation on two new species of Nematocystis Hesse, 1909 (Protozoa; Monocystidae) from earthworms (Annelida: Oligochaeta) of West Bengal, India. Anim Biol. 55: 133-139.

BANDYOPADHYAY, P.K., MALLIK, P. and MITRA, A.K. 2006. Nematocystis indica sp. n. (Protozoa: Apicomplexa: Eugregarinida). An endoparasitic monocystid gregarine from the seminal vesicles of an Indian earthworm Amynthas diffriengens Baird (Annelida: Oligochaeta) Protistol. 4: 35760.

BANDYOPADHYAY, P.K., MALLIK, P. and MITRA, A.K. 2007. Observations on Monocystis arabindae n. sp. and Nematocystis majumdari n. sp. (Protozoa: Apicompleaxa:Monocystidae) from Seminal Vesicles of an Earthworm Eutyphoeus incommodus (Beddard) from West Bengal, India. Acta Protozool. 46: 147-55.

BHATIA, B.L. and SETNA, S.B. 1926. On some more gregarine parasites of Indian earthworm. Arch. Protistenk. 53: 361-7.

CLOPTON, R.E. 2004. Standard nomenclature and metrics of plane shapes for use in gregarine taxonomy. Comp. Parasitol. 71: 130-40.

LEVINE, N.D. 1977. Revision and checklist of the species of the aseptate gregarine family Monocystidae. Folia. Parasitol. 24 : 41-52.

MALLIK, P. and BANDYOPADHYAY, P.K. 2009. Nematocystis bayrami sp. n. (Protozoa, Apicomlexa, Eugregarinida) monocystid gregarine from Eutyphoeus orientalis Beddard (Annelida, Oligochaeta) N-W. J. Zool. 5: 420-3.

MALLIK, P., BANDYOPADHYAY, P.K. and GÖÇMAN, B. 2010. Nematocystis vinodae n.sp. (Protozoa, Apicomplexa, Eugregarinida), a monocystid gregarine from Eutyphoeus nicholsoni (Beddard) Türkiye. Parasitol. Derge 34: 27-29.

PRADHAN, D. and DASGUPTA, B. 1980. Record of some new gregarines in earthworms from the hill areas of Darjeeling district-I. North Bengal Univ. Rev. (Sci. Tech.) 1: 135-139.

SEGUN, A.O. 1978. Monocystid gregarine parasites of Nigerian earthworms. J. Protozool. 25: 157-62.

(Manuscript received on September 29, 2011; revised on February 6, 2012) 